\title{
Identifying priority areas for the conservation of antelopes in the Republic of Guinea, West Africa, using the complementarity approach
}

\author{
D AVID BRUGIÈRE
}

\begin{abstract}
The Republic of Guinea has one of the highest diversities of mammal species in West Africa. However, its protected area network is poorly developed and little quantitative information has been available to help guide national conservation strategies. I therefore examined the distribution of antelopes and related species (families Bovidae and Tragulidae) across 17 sites, including four protected areas, to determine how the existing protected area network contributes to the conservation of antelope species and where action should best be focused for the conservation of this group. A total of 21 species of antelope have been recorded in the 17 sites; four of these species are absent from the four protected areas. An iterative heuristic complementarity approach was used to determine an irreplaceability index, which accounts for both species richness and species rarity, for each of the sites. The Kankan Faunal Reserve and Nimba Strict Nature Reserve have the second and fourth highest irreplaceability indices, respectively. The two other protected areas have moderate to very low irreplaceability indices, showing that they protect species widespread throughout the 17 sites. The Ziama Forest has the highest index (because it contains a high number of species and of globally threatened species), highlighting the significance of this site. I discuss the importance of the other sites and the threats affecting antelopes in Guinea, and make recommendations to improve the study and conservation of antelope species in the country.
\end{abstract}

Keywords Antelopes, Bovidae, Republic of Guinea, irreplaceability index, priority sites, Tragulidae, ungulates

\section{Introduction}

Ub-Saharan Africa supports $>70$ species of antelope, $\checkmark$ a much greater diversity than that of any other group of medium- to large-sized mammal species (East, 1999). Antelope communities in Africa play a key role in ecosystem functioning, both in the savannah and forest biomes, and are important for rural human communities, in particular as a source of bushmeat (Vbra \& Schaller, 2000). West Africa

DAVID BRUGIÈRE BRLI-SECA Consulting company, 1105 Avenue Pierre Mendes-France, 30001 Nîmes Cedex 5, France. E-mail dmc_brugiere@yahoo.fr

Received 12 October 2010. Revision requested 16 December 2010.

Accepted 10 February 2011. harbours c. $50 \%$ of the total species of African antelope (East, 1999) and, because of a high level of habitat degradation, habitat conversion to land crops, encroachment by livestock and hunting pressure, antelope populations are more threatened in this region than elsewhere in Africa (East, 1990, 1999). Thirteen of the 15 West African countries have lost at least one (and up to four) antelope species within the last 50 years (East, 1990). Conservation of antelope populations in West Africa is therefore a continental priority (East, 1999). The Republic of Guinea (hereafter Guinea) is one of the largest West African countries but its mammalian fauna is one of the least known (Barnett \& Prangley, 1997). Despite recent improvement in this knowledge (e.g. Brugière et al., 2005; Granier \& Kourouma, 2009) the status of antelopes in Guinea remains poorly known. The protected area network in Guinea is underdeveloped and excludes a large array of habitats and species (Brugière \& Kormos, 2009). The development of a representative protected area network is regarded as a priority by national authorities (IUCN, 2008). To provide key information on the most important sites for antelope conservation in Guinea I assess how the present protected area network contributes to the conservation of the country's antelope species and identify priority areas for conservation of these antelopes based on complementarity principles.

\section{Study area}

The Republic of Guinea covers $245,857 \mathrm{~km}^{2}$ from its western edge on the Atlantic coast south-eastwards in an arc into the interior of West Africa (Fig. 1). The country has five ecoregions: Western Guinean Lowland Forest in the south, Guinean Montane Forest along the mountainous ranges in the south and centre, Mangroves along the coast, Guinean Forest-Savanna Mosaic in the centre, and West Sudanian Savanna in the north (Burgess et al., 2004). Human population density is relatively high $\left(38.5 \mathrm{~km}^{-2}\right.$; World Atlas, 2010). The Western Guinean Lowland Forest is the most threatened ecoregion in the country (Burgess et al., 2004). Because of its large array of habitats, diversity in Guinea is high: on a species-per-area basis it has one of the highest diversities of mammals in West Africa (Barnett \& Prangley, 1997).

Until recently there have been few studies of the antelopes of Guinea. Based on an overview of literature 


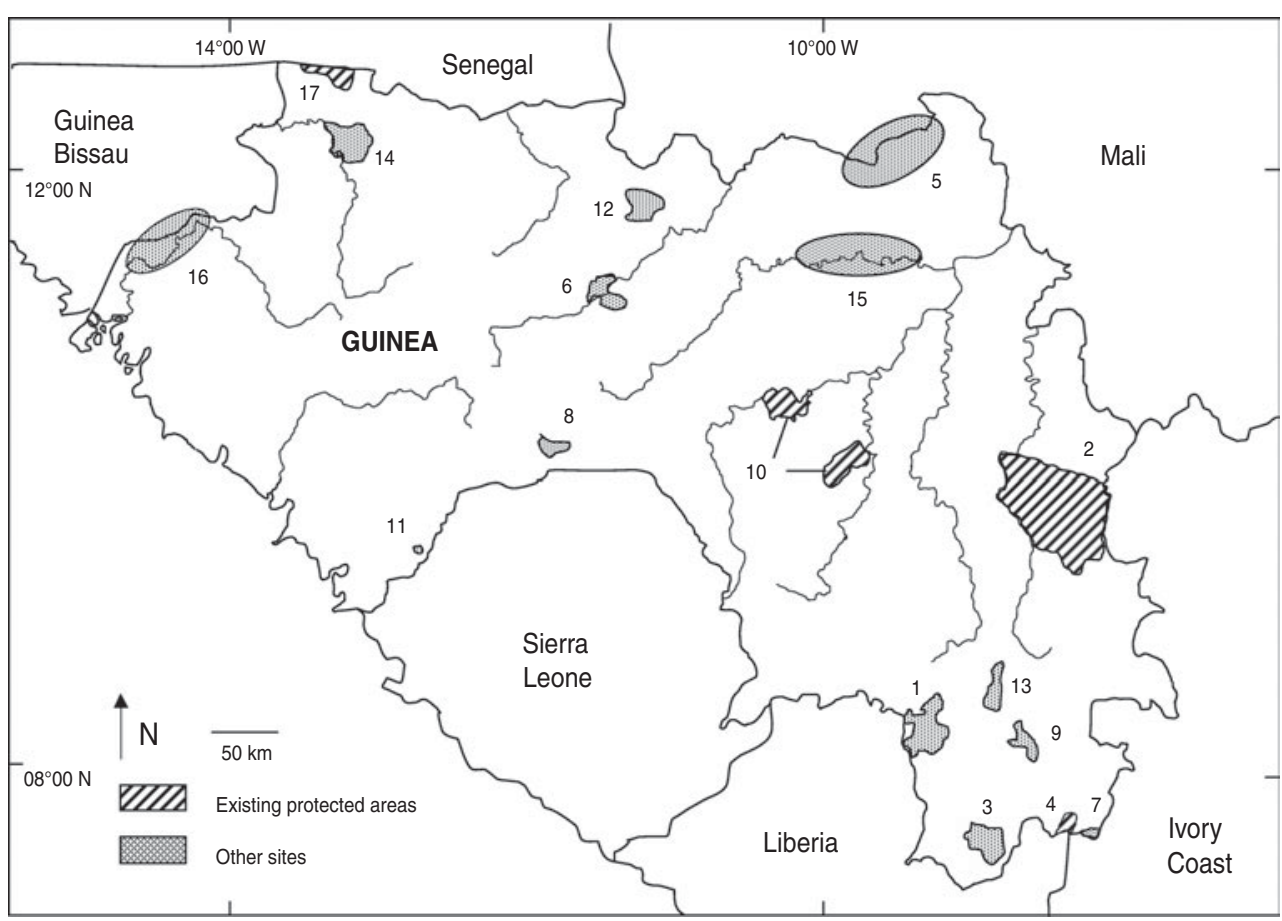

FIG. 1 Guinea, showing the 17 sites (see Table 1 for names and further details) for which antelope diversity was assessed. (including grey literature) for 1946-1996 Barnett \& Prangley (1997) proposed a preliminary checklist for the mammals of Guinea that included 23 species of Bovidae ( 22 species of antelopes including one species extinct in Guinea, the korrigum Damiliscus lunatus, plus the buffalo Syncerus caffer nanus) and one species of Tragulidae. When the Antelope Global Survey and Action Plan for West and Central African countries was published (Sournia et al., 1990) Guinea was the only country of 22 for which no detailed species account was available. This report listed a total of 18 species of antelopes occurring in Guinea (including the recently extinct korrigum). Between 2000 and 2010, although no country wide survey of the status of antelopes was conducted, biodiversity surveys implemented in the framework of conservation projects were carried out at several sites (Pelosi, 2000; Ziegler et al., 2002; Brugière et al., 2005; Wright et al., 2007a) and provide data of antelope occurrence.

\section{Method}

\section{Selection of areas}

A bibliographical review of sites with data available on biodiversity was undertaken and 17 sites were selected for inclusion in the analysis based on the availability of data on the occurrence of antelope species. These sites are distributed throughout the country and cover four of its five ecoregions (Fig. 1; no site with data on antelope occurrence was found in the Mangroves ecoregion). Four sites are protected areas (Haut Niger and Badiar National
Parks, Kankan Faunal Reserve, Nimba Strict Nature Reserve) and nine sites are Classified Forests (forests managed mainly for the production of timber). Three sites have no legal status but two of these (Bakoy and Kogon) have been proposed as components of transboundary protected areas (IUCN, 2008). The management of most of these 17 sites has been supported in recent years by natural resource management projects funded by international donors. The species lists used come from biodiversity inventories carried out in the framework of these projects. We focus on species of Bovidae and Tragulidae, hereafter referred to as antelopes. Species taxonomy follows Grubb (2005).

\section{Data analysis}

Priority areas for the conservation of antelope species were identified using complementarity principles. Analyses of complementarity use an iterative approach that maximizes unrepresented species among the species occurring in a set of study sites (Margules \& Sharkar, 2007). This allows calculation of an irreplaceability index for each study site. The index accounts for both species richness and species rarity (i.e. species found in a small number of study sites). Based on the formula initially proposed by Hartley et al. (2007) and modified here to take account of the Red List status of the species, the irreplaceability index $(I R)$ was calculated from:

$$
I R s=\sum_{i=1}^{t}\left(\frac{1 \times R s p}{N s p}\right)
$$


where $s$ is a study site, $N$ the number of study sites where species $s p$ is found, $t$ the total number of species considered in the analysis, and $R$ the Red List status of species $s p$. The Red List status refers to the 2009 IUCN Red List category, assigned a score ranging from 5 to 1 , with 5 for the most threatened species (Critically Endangered) and 1 for the Least Concern category. The higher the index, the higher the conservation significance of the study site.

\section{Results}

A total of 21 species of antelopes was recorded in the 17 study sites (Table 1). Seventeen of these have been observed in the four protected areas. The four species observed outside the protected area network are the zebra duiker Cephalophus zebra, the royal antelope Neotragus pygmaeus, the giant eland Tragelaphus derbianus and the bongo Tragelaphus eurycerus. The three most common species are Maxwell's duiker Cephalophus maxwelli (observed in all 17 sites), the bushbuck Tragelaphus scriptus and the yellow-backed duiker Cephalophus silvicultor (both observed in 15 sites), and the buffalo (14 sites). The three rarest species were observed in a single site: the giant eland in Bakoy, the Bohor reedbuck Redunca redunca in Kankan Faunal Reserve and the zebra duiker, categorized as Vulnerable on the IUCN Red List, in Ziama Classified Forest. With 14 species, the Kankan Faunal Reserve has the highest number of antelope species followed by the Bani-Dar Es Salam Classified Forest (12 species). Three sites have 11 species (Ziama and Pinseli Soyah Classified Forests, Nimba Strict Nature Reserve). Badiar National Park, with a single species, is the poorest site.

The Ziama Classified Forest has the highest irreplaceability index (Table 1). All other study sites have indices at least 50\% lower, highlighting the significance of Ziama for antelope conservation in Guinea. Ziama has both a high number of species $(n=11)$ and the three species in the data set that are globally threatened. The second most important site is the Fankan Faunal Reserve. It has the highest number of species of all the sites $(n=14)$ and contains rare species (the Bohor reedbuck Redunca redunca is found only in Fankan). The Nimba Strict Nature Reserve ranks fourth and the other two protected areas (Haut Niger and Badiar National Parks) have a low to very low irreplaceability index.

\section{Discussion}

I located information on 21 species of the families Bovidae and Tragulidae in Guinea. This is slighly less than the 23 extant species in the preliminary checklist of the country's mammals (Barnett \& Prangley, 1997). One of the two missing species, Ogilby's duiker Cephalophus ogilbyi, was included in the checklist on the basis of its mention in the list of mammals of the Ziama and Diécké forests (Bourque \&
Wilson, 1990, in Barnett \& Prangley, 1997). The biodiversity of these forests was intensively studied during 1991-1994 (Butzler, 1994) and this duiker species was not observed, suggesting that the species has gone extinct in these areas, that it has been overlooked because of an identification problem (Ogilby's duiker can be confused with the bay duiker Cephalophus dorsalis), or that its early mention in these two forests was in error. The second missing species, the red-fronted gazelle Gazella rufifrons was included in the national checklist only on the basis of its mention on the official list of protected species in Guinea. As there are no historical records of the species its occurrence in Guinea is unlikely. Our study confirms the occurrence in Guinea of Jentink's duiker Cephalophus jentinki, a species mentioned by Barnett \& Prangley (1997) but not by Sournia et al. (1990), East (1999) or Wilson (2005). This threatened species is reported in Ziama and Diécké Classified Forests (Butzler, 1994) and it was observed in 2009 in Mont Nimba Strict Nature Reserve and the nearby Déré Classified Forest (Granier \& Kourouma, 2009; N. Granier, pers. comm.).

The Ziama Classified Forest and the nearby Diécké Classified Forest have the highest and third highest irreplaceability index, respectively. This is because of their high number of antelope species and the occurrence of rare and threatened species. They contain typical rainforest mammal species (including several nationally and globally threatened species such as the elephant Loxodonta africana); Ziama Classified Forest has been proposed as a National Park (Brugière \& Kormos, 2009). The protected area network of Guinea currently protects 17 of the 21 antelope species known to occur in the country. However, two of the four protected areas have moderate to very low irreplaceability indices, showing that the species in these areas are widespread throughout the 17 sites.

Kankan Faunal Reserve has the second highest irreplaceability index. This site holds the highest number of antelope species of all the sampled sites and contains one species (the bohor reedbuck) not found in any other site in Guinea (although it is widespread in West Africa; East, 1999). The high number of species is explained by the large size of the reserve $\left(5,314 \mathrm{~km}^{2}\right)$ and its diversity of habitats and because it straddles the Guinean Forest-Savanna Mosaic and West Sudanian Savanna ecoregions. This protected area has, however, received little attention and is essentially a socalled paper park: it has no staff, no management plan and $>_{20,000}$ people live within it (Dufour, 2008). As a result, poaching pressure is high and antelope population densities, as inferred from encounter rates, are very low (Butzler, 1994; Dufour, 2008). The legal status of the Reserve, which dates from 1926, is outdated and needs to be brought into line with current protected area legislation (Brugière \& Kormos, 2009). Although the effective contribution of this Reserve to the conservation of antelopes in Guinea is limited because of a lack of law enforcement, its high irreplaceability index 


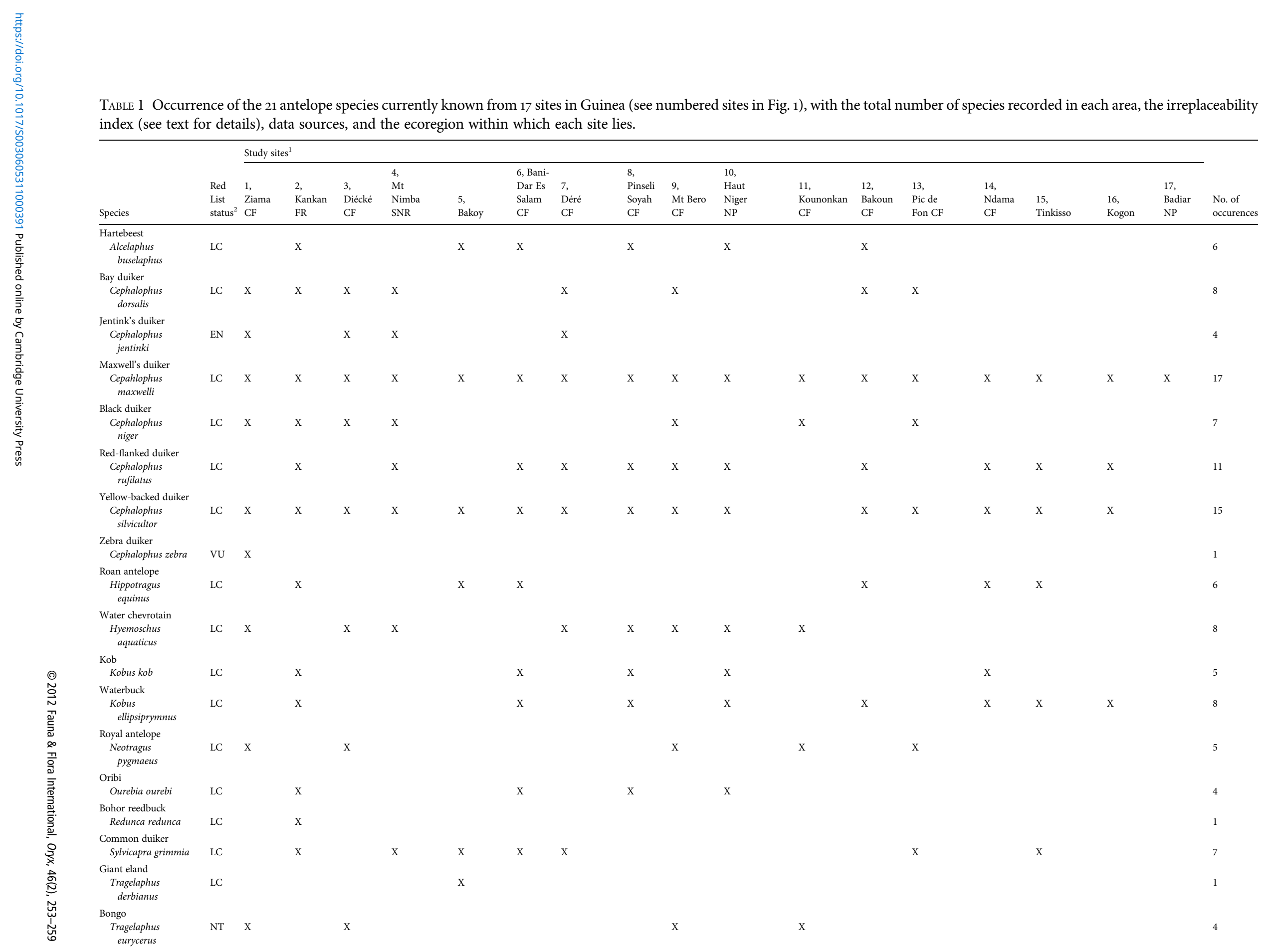




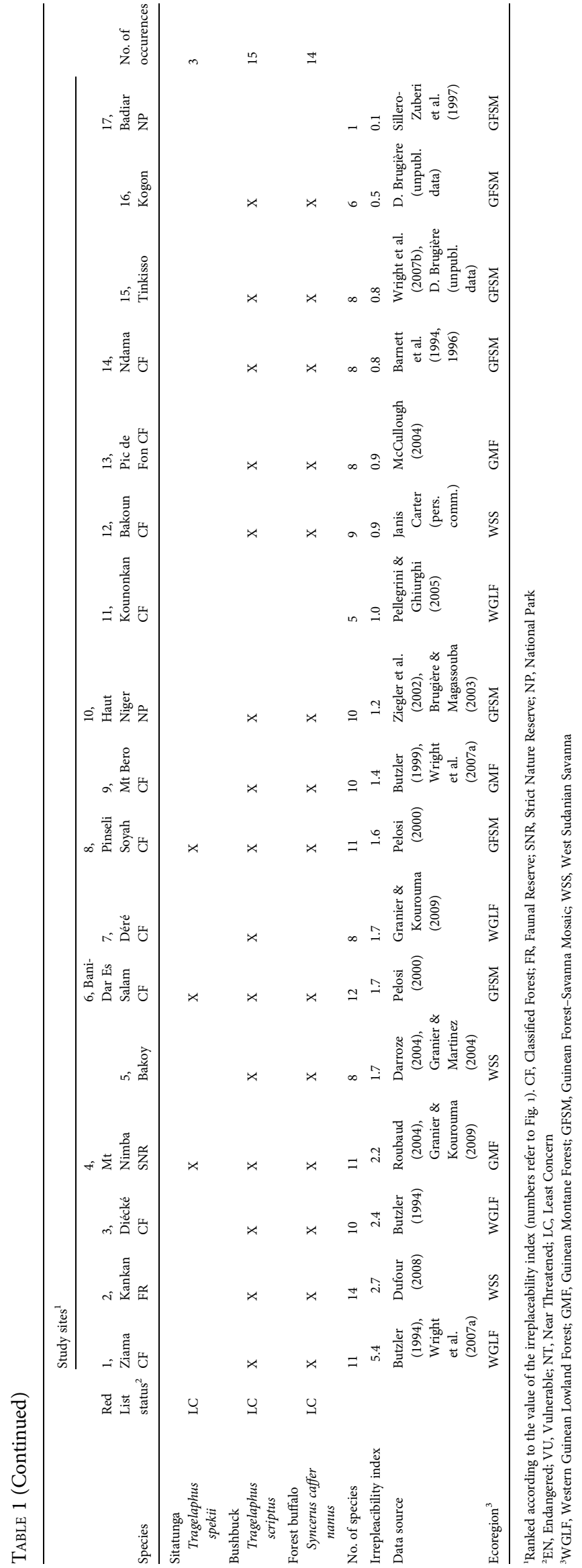

highlights its significance. The rehabilitation of the reserve, already identified in 2001 as a key action in the National Biodiversity Action Plan (MMGE, 2001), remains a priority. This will need to include a revision of its boundaries to exclude areas with high human population densities.

Antelopes are under high pressure in Guinea. Bushmeat hunting and trade are widespread and are the most serious threats to the conservation of large- and medium-sized mammals, in particular ungulates (IUCN, 2008). Although no nationwide survey has been carried out, local surveys have shown that antelopes account for a significant proportion of meat traded. Around Haut Niger National Park at least $170,000 \mathrm{~kg}$ of bushmeat are traded annually; antelopes (seven species) and buffalo accounted for $51 \%$ and $69 \%$ of the carcasses $(n=9,134)$ and biomass traded, respectively (Brugière \& Magassouba, 2009). Dufour (1999) found similar results around Nimba Special Nature Reserve where ungulates (eight antelope species, buffalo and red river hog Potamochoerus porcus) accounted for $54 \%$ of the carcasses traded $(n=110)$. Virtually every farmer in Guinea possesses firearms and hunts year-round. Combined with the high human population density, this results in a low abundance of large- and medium-sized mammals throughout the country. Hunting plays an important social role in rural areas and traditional hunters belong to active associations (Pailler et al., 2009) but hunting regulations are poorly enforced and, because of political instability, the situation in unlikely to change rapidly. Habitat destruction also threatens the antelopes. There are no large tracts of unfragmented habitats, and rainforests, the most threatened vegetation type in Guinea (Burgess et al., 2004), have been largely cleared for agriculture over the last 20 years. The Ziama and Diécké Classified Forests are now the two largest unfragmented forest blocks in Guinea (FAO, 2005).

The irreplaceability index was based on the occurrence of species. To avoid bias the occurrence of species in a set of sites should ideally be determined with the same method and the same sampling intensity because these two parameters significantly influence the detection of species (Wilson et al., 1996). All sites included in this study have not been surveyed with similar intensity; studies range from intensive surveys over several years (e.g. in Ziama and Diécké Classified Forests) to short surveys based on interviews with local hunters (e.g. in Tinkisso). It is therefore likely that additional species of ungulates occur in sites where sampling effort has been low; observation of further species could potentially modify the irreplaceability index of such sites. The index is also dependent on the taxon level used. Subspecies occurring in Guinea may have a Red List category different from that of the nominal species. For example, the giant eland is categorized as Least Concern globally but as a Critically Endangered subspecies in West Africa (T. derbanius derbanius). Using this subspecies Red 
List category the Bakoy site has the highest irreplaceability index because it is the only site with the giant eland. A further limitation of the analysis is that some ecoregions are better represented than others in the data set. Other important sites for the conservation of antelopes in Guinea may yet be indentified.

To improve this assessment of the conservtion status of the antelopes of Guinea I make two recommendations. Firstly, a survey of the distribution and status of antelopes should be carried out throughout Guinea. Staff from the protected areas and the local offices of Direction Generale des Eaux et Forêts (the institution in charge of forest management in Guinea) could be trained to implement such a survey. Pelosi (2000) used a combined interview and field survey method that was implemented by local staff in two classified forests in Guinea. This approach, once refined, could be used to design an appropriate survey methodology for Guinea. A similar nationwide survey of chimpanzees, based on interviews and limited field surveys, was conducted in the late 1980s in Guinea (Sugiyama \& Soumah, 1988) and subsequent more intensive field studies revealed that the results were reliable (Ham, 1998). A nationwide survey of antelopes would faciliate establishment of a national antelope Red List. Secondly, key sites for antelope conservation need to be incorporated into a national conservation planning exercise to prioritize key biodiversity areas. In such a densely populated country the strengthening of the protected area network (both in terms of number of protected areas and management efficiency) is the most viable option for the long-term conservation of the full community of large- and medium-sized mammals. Such recommendations have been endorsed by the national authorities in charge of biodiversity conservation and a strategic plan for the strengthening of the protected areas network is currently in preparation.

\section{Acknowledgements}

I thank Sylvain Dufour, Philippe Chardonnet, John Oates and two anonymous reviewers for valuable comments.

\section{References}

Barnett, A.A. \& Prangley, M.L. (1997) Mammalogy in the Republic of Guinea: an overview of research from 1946 to 1996, a preliminary checklist and a summary of research recommendations for the future. Mammal Review, 27, 115-164.

Barnett, A., Prangley, M., Hayman, P., Diawara, D. \& Konan, J. (1994) A preliminary survey of Kounounkan Forest, Guinea, West Africa. Oryx, 28, 269-275.

Barnett, A., Prangley, M., Hayman, P., Diawara, D. \& Konan, J. (1996) A survey of the mammals of Kounounkan massif, SouthWestern Guinea, West Africa. Journal of African Zoology, 110, 235-240.

Brugière, D., Dia, M., Diakité, S., Gbansara, M., Mamy, M. \& Magassouba, B. (2005) Large- and medium-sized ungulates in the
Haut Niger National Park, Republic of Guinea: population changes 1997-2002. Oryx, 39, 50-55.

Brugière, D. \& Kormos, R. (2009) Review of the protected area network in Guinea, West Africa, and recommendations for new sites for biodiversity conservation. Biodiversity and Conservation, 18, 847-868.

Brugière, D. \& Magassouba, B. (2003) Mammalian diversity in the National Park of Upper Niger, Republic of Guinea-an update. Oryx $, 37,3$.

Brugière, D. \& Magassouba, B. (2009) Pattern and sustainability of the bushmeat trade in the Haut Niger National Park, Republic of Guinea. African Journal of Ecology, 47, 630-639.

Burgess, N., D’Amico Hales, J., Underwood, E., Dinerstein, E., Olson, D., Itoua, I. et al. (2004) Terrestrial Ecoregions of Africa and Madagascar - A Conservation Assessment. Island Press, Washington, DC, USA.

BUtZler, W. (1994) Inventaire des mammifères des deux massifs forestiers Ziama et Diécké. Rapport pour le PROGEFOR. PROGEFOR, Sérédou, Guinée.

Butzler, W. (1999) Conservation de la biodiversité. Rapport de la mission d'appui juillet-septembre 1999. Rapport pour le PROGEFOR. PROGEFOR, Sérédou, Guinée.

Darroze, S. (2004) Western giant eland (Tragelaphus derbianus derbianus) presence confirmed in Mali and Guinea. In Antelope Survey Update $N^{\circ} 9$ (November 2004) (eds B. Chardonnet \& P. Chardonnet), pp. 21-23. International Game Foundation, Paris, France.

Dufour, S. (1999) Inventaire et gestion du patrimoine faunistique de la réserve de biosphère des monts Nimba. Mission préliminaire juillet-aout 1999. Rapport pour le CEGEN. CEGEN, Conakry, Guinea.

Dufour, S. (2008) Programme de gestion communautaire et participative de la faune sauvage dans la Réserve de Faune de Kankan, République de Guinée. Rapport de mission. Sylvatrop, Conakry, Guinea.

EAST, R. (ed.) (1990) Antelopes: Global Survey and Regional Action Plans. Part 3: West and Central Africa. IUCN, Gland, Switzerland.

East, R. (1999) African Antelope Database. Occasional Paper of the IUCN Species Survival Commission $N^{\circ} 21$. IUCN, Gland, Switzerland.

FAO (Food and Agriculture Organization of the UN) (2005) State of the World's Forests 2005. FAO, Rome, Italy.

Granier, N. \& Kourouma, M. (2009) Disparities in the Nimba Mountain Biosphere Reserve: New Perspectives on the Conservation of Large and Medium-Sized Mammals. Report to CEGEN. CEGEN, Conakry, Guinea.

Granier, N. \& Martinez, L. (2004) Etude des chimpanzés de l'aire protégée "Bafing-Falémé": enquêtes auprès des populations locales et dénombrement par comptages de nids. Rapport pour le programme AGIR. Programme AGIR, Bamako, Mali.

Grub B, P. (2005) Artiodactyla. In Mammal Species of the World. A Taxonomic and Geographic Reference (eds D.E. Wilson \& D.M. Reeder). The Johns Hopkins University Press, Baltimore, USA.

Ham, R. (1998) Nationwide Chimpanzee Census and Large Mammal Survey in the Republic of Guinea. Report for the European Union. European Union, Conakry, Guinea.

Hartley, A.J., Nelson, A., Mayaux, P. \& Grégoire, J.-M. (2007) The Assessment of African Protected Areas. JRC-IES, Ispra, Italy.

IUCN (2008) Evaluation de l'efficacité des aires protégées-Aires protégées de la République de Guinée. IUCN BRAO, Ouagadougou, Burkina Faso.

IUCN (2011) IUCN Red List of Threatened Species v. 2011.2. Http:// www.iucnredlist.org [accessed 10 February 2012]. 
Margules, C. \& Sharkar, S. (2007) Systematic Conservation Planning. Cambridge University Press, Cambridge, UK.

McCullough, J. (ed.) (2004) Une évaluation biologique rapide de la forêt classée du Pic de Fon, chaîne du Simandou, Guinée. Bulletin RAP d'Evaluation Rapide No. 35. Conservation International, Washington, DC, USA.

MMge (Ministère des Mines, de la Géologie et de L'Environnement) (2001) Stratégie Nationale et Plans d'Actions de la Diversité Biologique. MMGE, Conakry, Guinée.

MTPE-DNe (Ministère des Travaux Publics et de L'Environnement-Direction Nationale de L'Environnement) (1997) Monographie Nationale sur la Diversité Biologique. MTPE-DNE, Conakry, Guinée.

Pailler, S., Wagner, J.E., McPeak, J.G. \& Floyd, D.W. (2009) Identifying conservation opportunities among Malinké bushmeat hunters of Guinea, West Africa. Human Ecology, 37, 761-774.

Pellegrini, A. \& Ghiurghi, A. (2005) Mission d'appui pour l'élaboration du plan d'aménagement du Parc National du Badiar. Rapport pour le Programme AGIR. Programme AGIR, Conakry, Guinée.

Pelosi, A. (ed.). (2000) Enquête communautaire de reconnaissance faunistique des forêts classées de Pinselli et Dar-es-Salam dans la préfecture de Mamou. Rapport pour le PRABV. PRABV, Conakry, Guinée.

Roubaud, S. (2004) Recherche de stratégies de gestion durable de la faune des monts Nimba (Guinée). Thèse Vétérinaire. Muséum National d'Histoire Naturelle, Paris, France.

Sillero-Zuberi, C., Silvestre, I.D., Marino, J., Massaly, S. \& Novelli, O. (1997) La distribution et l'abondance de quelques espèces clés de mammifères dans le Niokolo Badiar. Rapport pour le PRABV. PRABV, Conakry, Guinée.

Sournia, G., East, R. \& Macky, L. (1990) Guinea. In Antelopes: Global Survey and Action Plan: Part 3. West and Central Africa. (ed. R. East), pp 38-39. IUCN, Gland, Swizterland.
Sugiyama, Y. \& Soumah, A.G. (1988) Preliminary survey of the distribution and population of chimpanzees in the Republic of Guinea. Primates, 29, 569-574.

Vbra, E. \& Schaller, G.B. (2000) Antelopes, Deer and Relatives: Fossil Record, Behavioral Ecology, Systematics and Conservation. Yale University Press, New Haven, USA.

Wilson, D.E., Cole, F.R., Nichols, J.D., Rudran, R. \& Foste R, M.S. (1996) Measuring and Monitoring Biological Diversity: Standards Methods for Mammals. Smithsonian Institution Press, Washington, DC, USA.

Wilson, V.J. (2005) Duikers of Africa. Zimbi Books, Harare, Zimbabwe.

World Atlas (2010) Population Density of the Countries of the World. Http://www.worldatlas.com [accessed 15 April 2009].

Wright, H., McCullough, J. \& Diallo, M.S. (eds) (2007a) A Rapid Biological Assessment of Three Classified Forests in Southwestern Guinea. Bulletin RAP of Biological Assessment No. 4o. Conservation International, Washington, DC, USA.

Wright, H., McCullough, J. \& Diallo, M.S. (eds) (2007b) A Rapid Biological Assessment of Boké Préfecture, Northwestern Guinea. Bulletin RAP of Biological Assessment No. 41. Conservation International, Washington, DC, USA.

Ziegler, S., Nicholaus, G. \& Huterrer, R. (2002) High mammalian diversity in the newly established National Park of Upper Niger, Republic of Guinea. Oryx, 36, 73-80.

\section{Biographical sketch}

DAVID BRUGIËR is a tropical ecologist. After working on the ecology and conservation of rainforest biodiversity in Central Africa for 7 years he was appointed the principal technical adviser of two EU-funded protected area projects in Guinea, from 2000 to 2004 . He is now working as biodiversity project officer at BRLi consulting company, France. He is a member of the IUCN/Species Survival Commission Primate and Antelope Specialist Groups. 